Félix Armando Nú̃ez

\title{
La vivencia espiritual de don Enrique Molina ${ }^{(*)}$
}

\section{A MODO DE PROLOGO}

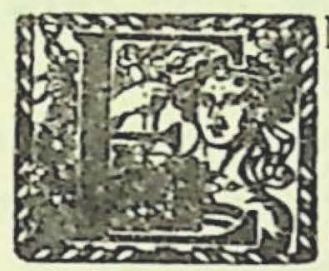

LOS ALBORES de nuestra juventud, cuando oscilábamos entre una actitud escéptica y una interpretación materialista de la realidad, ajenos a todo dogmatismo como sólo suele acontecer en la soledad y el aislamiento, leímos esta frase impresionante de Eugenio d'Ors: "Hay que estar hablando siempre del Espíritu, aunque no sepamos bien lo que es". Nunca se nos ha olvidado la oportuna e inspirada admonición.

También en ese entonces tuvimos el honor y la fortuna de comenzar nuestra carrera pedagógica al lado de don Enrique Molina, y junto a él vivimos un cuarto de siglo, recibiendo como es natural su saludable y edificante influencia de cada momento.

Tal vez el ahora longevo rector de la Universidad de Concepción y notable comentador de Guyau y Bergson, no había leído la bella recomendación del ensayista y crítico catalán. Lo cierto es que ha vivido sesenta años actuando como bajo el imperativo íntimo de análoga consigna.

(*) Con motivo de sus últimas obras: Tragedia y realización del espíritu y La filosofia en Chile en la primera mitad del siglo XX. 
Sí. Hay que estar hablando siempre del Espíritu, porque de otra manera no existiría, añadimos nosotros sin ninguna intención paradójica ni reticente. Recordemos al pasar que Aristóteles derivó del lenguaje articulado y sus categorías la superioridad de la razón humana para hacerla lindar con lo divino en la contemplación intelectual. Y en la Sagrada Escritura el principio era el Verbo.

Por los valores espirituales, De lo espiritual en la vida humana rezan los títulos de dos obras de don Enrique Molina, a guisa de empresas temerarias con que dentra de la atmósfera de comienzos de nuestro siglo, muy cercana de la estratósfera, comienza a campear este nuevo Don Quijote chileno contra el positivismo filosófico en que se había echado a dormir una siesta soporosa la mentalidad de fines de la anterior centuria.

"Por el desarrollo libre del Espíritu" clama, como el crepitar de un fuego, el lema de la Universidad de Concepción, cifrado en una realidad magnífica y perdurable, conquistada a pesar de todo para Dulcinea.

\section{I}

\section{DIFICIL POSICION}

Venía don Enrique Molina del mundo de fines del siglo XIX, en que las religiones positivas y el cientismo se repartían las conciencias como dos hemisferios excluyentes. Pero había en él una inquietud metafísica llena de moderación, característica de su vida entera, que no se avenía ni con los dogmas de la fe, ni menos con la afirmación igualmente dogmática de que había que volver la espalda a los problemas de la Filosofía Primera.

En esta situación anímica lo toma el flujo de la marea en el movimiento de vaivén eterno, de pendular oscilación que es toda la vida profunda del individuo y las sociedades en el devenir histórico: la violenta necesidad de compensar a Don Quijote con Sancho, y a éste con el hidalgo iluso; el imperativo vital y por ende irresistible de 
enaltecer lo que se había menospreciado o preferido; el ritmo poderoso entre los extremos con que Heráclito definió para siempre el estilo de la realidad cósmica.

El flujo va a culminar ahora en la ola gigante de Bergson, rumorosa de inauditas armonías, centelleante de imágenes de sol, cororada de espumas estelares en la suprema tensión del "tiempo vivo". El sentimiento relegado a segundo término, la pasión estética desplazada por la sobrevaloración de la ciencia, la fantasía exaltada en un vuelo libérrimo más allá de las fronteras del espacio; he aquí lo que trae la marea al comenzar el siglo. La reivindicación del Espíritu, y luego lo contrarracional, lo intuido y hasta lo arbitrario. La angustia que, según la expresión más tardía de Heidegger, saca al hombre de la vida trivial.

Hemos enseñado muchas veces que toda la lucubración filosófica tiene en gran dosis carácter subjetivo. En ella es determinante el temperamento del pensador. Un poeta inmenso como Platón no podía concebir la realidad sino hecha de la substancia de los sueños radiosos y los más puros ideales. Un hombre de ciencia al estilo de Aristóteles debía ser necesariamente objetivo.

El carácter de don Enrique Molina es más del linaje de Aristóteles y de su maestro remoto Sócrates que de la estirpe de Platón o del poeta de "I a evolución creadora". Sin embargo, la intuición del Espíritu es una vivencia permanente y lúcida en su conciencia apasionada de la Cultura.

Admira a James y a Bergson, pero no se les entrega. La razón o inteligencia para él es cosa seria en cuanto poder de filosofar.

¿Cómo explicar, pues, racionalmente la realidad del Espíritu que él vive como energía inspiradora de sus pensamientos, de su actitud, de su fe en el porvenir, de la constancia en el esfuerzo que plasma una obra de vastas y fecundas proyecciones?

Contemporáneamente con su inquietud vigilante de medio siglo aparecen en la Vieja Europa la axiología o teoría de los valores y el existencialismo. Ahí están de un lado, deslumbrantes, Hartmann y Scheler. Del otro, inquietadores, Heidegger, Jaspers. 
En ambas escuelas desfilan ideas coincidentes con las suyas. Más en la primera que en la segunda. No obstante hay una línea central diversa, la línea del temperamento y de la vida vivida que constituye como el eje en torno al cual rotará su cuerpo de interpretaciones. Pero antes de examinarlas, detengámonos brevemente en algunos conceptos previos.

\section{I I}

\section{ALMA Y ESPIRITU}

La filosofía de nuestro tiempo - la representación de la épocaestablece distinción entre "alma" y "espíritu”. También están dotados de alma o vida anímica los brutos. El espíritu, o sea, la potencia de crear valores y estimarlos o intuirlos, es privativa de la especie humana. Sólo el hombre valora el Bien, la Verdad, el Amor, la Belleza, la Justicia, e inspirado en ellos crea la Cultura.

La Cultura es, por consiguiente, el Espíritu objetivado.

Análoga discriminación hizo Aristóteles al afirmar en nosotros la existencia de un intelecto pasivo (que todos los animales poseen) y un intelecto activo o alma racional, privilegio del hombre, que permite al filósofo la contemplación divina.

La teoría de los valores resulta, pues, la filosofía de la Cultura o la filosofía del Espíritu. Lo extraño y desconcertante en ella radica en el aserto de que los valores no "son", sino que "valen". No son "entes" sino "valentes". Es un modo de evitar la identidad con la doctrina platónica.

\section{V}

\section{CULTURA Y CIVILIZACION}

Unicamente Oswald Spengler, que sepamos nosotros, hace, entre los pensadores célebres, diferencia entre cultura y civilización. Su 
manera de sentirlas como cosas distintas no nos convence en muchos aspectos, pero sí en lo esencial. Relaciona la cultura con el instinto creador, un poco "Voluntad de poderío" a lo Nietzsche. La civilización con la decadencia de ese instinto. Esta última es sólo aprovechamiento mecánico de los efectos de la cultura y sus grandes conquistas.

Nosotros advertimos claramente la diferencia con alguna variante. Cultura y Civilización conviven o pueden convivir.

De acuerdo con las ideas de los más ilustres axiólogos, que don Enrique Molina comparte con entusiasmo, consideramos que la Cultura se origina en la creación y estimación de valores ("valores espirituales"). Pero el descubrimiento de valores, supone según Ortega y Gasset, una "facultad estimativa". Es decir, una sensibilidad fina y hasta excepcional. Al hombre corriente no se le ocurre dedicarse a la ciencia pura, al arte desinteresado, a una vida de santidad.

La civilización tiene como fundamento la técnica o ciencia aplicada. Somos civilizados porque viajamos en avión, alojamos en un décimo piso, oímos radio, vemos cintas cinematográficas, etc. Pero sólo somos "cultos" en la medida en que amamos la Verdad y la Justicia, en que sentimos o creamos la Belleza, en que nos apasiona hacer el Bien.

Así no nos parece extravagante sostener que el artista que dibujó en la cueva de Altamira maravillosas figuras de animales era más "culto" que la inmensa mayoría de los hombres actuales de cualquier país civilizado.

Individualidades egregias - figuras de excepción así, desde la tribu y quizás hasta desde la caverna- han ido creando Religión, Filosofía, Ciencia Pura, Arte, Derecho, Economía.

De otra manera sería inexplicable la cultura de hoy. 


\section{V \\ "EL CREACIONISMO HUMANO" DE DON ENRIQUE MOLINA}

¡El hombre! He aquí la clave de toda explicación filosófica para don Enrique Molina. El hombre, con su angustia sí; pero también con su voluntad creadora, razón y sentido de su existencia; con su dionisíaca alegría de hacer; con su dignidad moral, su capacidad de amor y su maravillosa libertad interna. Por eso entre los filósofos antiguos encuentra los paradigmas en Sócrates y sus legítimos herederos, los estoicos.

En el fondo y continuando esta tradición ilustre, sus libros todos y especialmente Tragedia y realización del espíritu constituyen una apoteosis casi poemática del esfuerzo, de la tensión de la voluntad.

Los valores, la cultura, el espíritu son creaciones humanas.

La revolución copernicana que Kant realizó al proponer fundar la metafísica en la moral, y no a la inversa como hasta entonces lo había intentado la filosofía clásica, reaparece en la admirable tentativa del pensador chileno con un brío, una forma y una belleza nuevos.

Así el espectáculo de la Cultura, de que es parte su propia obra, tan importante en América, lo induce a preguntarse de dónde saca el hombre esta "pasión fría", esta entusiasta voluntad creadora, este "eros" hacia el valor Amor que origina las religiones, hacia el valor Belleza que inspira el Arte, hacia el valor Verdad que anima a la Ciencia y la Filosofía.

Su vivencia del espíritu es para él la manifestación de su realidad inmediata. Pero iqué realidad tan superior a la animalidad del hombre! Trasciende de su "existencia trivial". De ahí que "el pienso, luego existo" de Descartes le parezca insuficiente. ¿Cómo intuir la evidencia de su existir profundo, sin sentirse inmediatamente solidario con cuanto le rodea? No; "pienso, luego existo y el ser existe". 
El pensador ha dado su gran salto. De la premisa psicológica ha pasado a la afirmación de la realidad cosmológica que aquí se identifica con la ontológica. ¿Y ahora?

Ahora la afirmación temperamental, entrañada, personalísima de su atrevida y bella especulación filosófica: El Espíritu se encuentrés en potencia en el ser, y es todo "tensión", "esfuerzo", "voluntad" como la razón o logos en la doctrina del Pórtico. Como el resorte interno que hace evolucionar la semilla hasta el árbol.

Mas, mientras en la teoría estoica la razón penetra todo el cosmos y viene a resultar el alma universal, el Espíritu en la meditación de don Enrique Molina no se manifiesta sino a través del hombre. Oigámosle en algunos pasajes:

"El Amor es el delirio dionisíaco con que el Ser celebra su perpetuación. En el fondo y origen de las cosas y de la vida columbramos un "imperativo de existencia". Es una fuerza misteriosa. No podremos saber por qué existe, o por qué más bien no existe nada. Es, como gustéis. El Uno, lo Absoluto, el principio divino, el fondo espiritual primitivo. Es la esencia de la sustancia única, cuyos aspectos son la materia o extensión y el espíritu o pensamiento. "El espíritu es la expresión de la mayor superación de la sustancia”.

"Con el hombre hizo su aparición la estructura superior del Ser, y este hecho trascendental vino a darle un sentido: porque la busca de un sentido de la vida y sus derivaciones son un problema exclusivamente humano".

"El problema esencial del hombre es la realización de su vida espiritual... Lo espiritual existe y existirá mientras aliente el hombre, como una función de nuestro ser, función que supone la actividad orgánica de la sustancia primitiva".

"Suponiendo aún que existiera un espíritu universal, éste no se manifestaría para nosotros sino por medio del hombre y a través del hombre".

"De entre las funciones del Ser, al hombre le cabe una específica: la espiritual. Esta es para él una dimensión propia. Todo lo material lo encuentra el hombre hecho, sin perjuicio de que en su reino terres- 
tre pueda llevar a cabo en este orden transformaciones y progresos estupendos. También encuentra todas las formas de vida vegetal y animal, y se ha mostrado hasta ahora fuera de su poder reproducir la más insignificante de ellas $y$, más aún, agregar una nueva. Pero le queda una rica compensación, le queda el Espíritu. Al revés de lo que pasa con la materia y la vida, sólo lo espiritual no se halla definiti vamente hecho y espera para su alumbramiento que nosotros lo vayamos realizando. También en todo el ámbito de nuestras observaciones sólo a través del hombre vemos, a pesar de la pequeñez humana, llevar a cabo propósitos, creaciones, designios reflexivos. El hombre tiene el arduo destino de aparecer, en medio de las confusas y entreveradas fuerzas del mundo, como cooperador de la creación, como vértice a que convergen corrientes secretas para encender en él las lámparas del Espíritu. De la inmanencia de la conciencia creadora viene a irradiar la más infinita trascendencia. Si los hombres no escuchan a Dios en su conciencia, no lo sienten ni lo realizan en ninguna parte. Pensando tal vez en algo semejante, dijo el místico que el reino de Dios está dentro de nosotros. Nos parece que por las buenas creaciones lo humano a veces se diviniza y que lo divino, buscando hacerse real, desciende a humanizarse. Hemos dicho en líneas anteriores que la divinidad se encuentra inmanente en el seno del Ser en cuanto éste alberga al espíritu en potencia. No se halla lejos esta concepción de la de Javier Zubirí, que, apartando de Dios los atributos de perfección y omnisciencia con que lo reviste la filosofía tradicional, lo llama ente fundamental o fundamentante. Con esto se libra por otra parte de la responsabilidad de la creación. Los males e imperfecciones del mundo son inconciliables en verdad con la creencia de que el universo proceda de una creación planeada de una vez y para siempre por un ser perfecto. Creo si que, completando la idea de Zubirí, se le debería llamar a Dios, además, ente compañero o acompañante. Aquí hay lugar para el amor, hay una indescifrable solidaridad en un porfiado destino de dolor y renovación. La creación no tiene fin; se sigue haciendo, y en esta faena infinita el hombre es colaborador de Dios". 


\section{LA ESFINGE}

Joven de 80 años se ha dicho hace poco de don Enrique Molina. Su espíritu alerto, vigilante, no cesa de informarse con avidez de cuanto se piensa y se escribe en el mundo entero. Su camino es, sin embargo, la senda recta, dorada de sol y orillada de árboles primaverales, por donde transita un poderoso temperamento creador, lleno de optimismo en el porvenir de la humanidad. Ha andado felizmente largas etapas, ha tenido que trepar denodadamente arduas cuestas y aspira a alcanzar la cumbre para contemplar el panorama recorrido. Pero he aquí de pronto un viandante inesperado, que quiere convencerlo de que nuestra vida carece de sentido, que estamos perdidos en el Universo, que el ser del hombre es para la muerte, que la existencia individual y concreta, la única real, se halla transida de la angustia de la nada. Este desviador inquietante ha mostrado con su índice la Esfinge. Lo hemos dicho en un verso: "Al final del camino la Esfinge está en acecho".

El pensador chileno está muy seguro de sí mismo para vacilar o sorprenderse siquiera. Eso lo sabía al inaugurar su peregrinación a través de las cosas. Lo sabemos todos. Aún más; el monstruo enigmático que devora sin cesar la existencia personal es la causa más importante de la tragedia del Espíritu. Porque "con el surgir de la razón, hasta ahora la más lograda realización del Espíritu, comienza desde ese punto la tragedia de éste".

"De ninguna manera logramos aquietar definitivamente nuestras inquietudes y la Esfinge sigue indisipable al frente de nosotros como una sombra que acompaña a la razón en todos sus pasos, como muro de sombras".

Por eso, "a la realización del Espíritu la precede siempre una etapa dolorosa, a veces superada, a veces no". 
Es como el dolor del alumbramiento natural, diremos recordando la mayéutica socrática y dentro del pensamiento voluntarista de don Enrique Molina el mayor acicate para probar el temple del carácter viril.

\section{I I}

\section{EL DESTINO VENCIDO}

Es imposible vencer a la Esfinge. No hay Edipo de la razón especulativa capaz de precipitarla.

El problema que propone es de los que carecen de solución, y como en la vida práctica, frente a ellos no quedan otras actitudes que la paciencia, la firmeza y la serenidad.

Pero el Destino, nuestro destino de dolor a que nadie escapa, sí puede ser vencido, cuando se escucha la voz de Dios, e! "ente compañero o acompañante" como don Enrique Molina lo llama con tan familiar belleza.

Toda la lucubración filosófica que venimos comentando se desenvuelve en nuestra imaginación como una sinfonía maravillosa. Recordamos la "Quinta de Beethoven y su implícita motivación: Por el dolor a la alegría”.

"El Espíritu -comenta nuestro pensador- tiene que sacar de sí mismo las fuerzas para sobreponerse a su angustia y ésas las encuentra en sus virtudes y en dos realizaciones supremas: el amor desinteresado y el valor.

"La Esfinge se torna sombra amiga y propicia si tenemos valor hasta para saber morir, si sabemos ser buenos hasta el fin".

Mas el avance victorioso de esta sinfonía beethoveniana no podrá detenerse aquí. Recoge los acordes más prometeicos del optimismo, atravesados de luces del cielo, gozosos de rojas rosas de sangre exultante, y como una réplica al desolado cuadro con que en "El jardín de Epicuro" Anatole France presiente el fin de la cultura creada por una especie de la cual no sobreviven en el planeta en- 
friado hasta el ecuador, sino unos pocos ejemplares de frente achatada y expresión obtusa que no tienen la menor idea de Homero ni las catedrales góticas. Don Enrique Molina, el maestro inspirador y entusiasta, el realizadar infatigable, el portador de la inextinguible antorcha, concluye con este acorde que toca en lo sublime:

"Cabe un último atisbo. Después de un tiempo remoto, remotísimo, tras el rodar de millares de siglos, es posible que por una causa u otra esta maravillosa vida se extinga en ì Tierra, y que las prodigiosas creaciones del hombre caigan en una destrucción equivalente a la nada. Esta catástrofe la divisamos tan lejos que apenas nos conmueve. Pero no es improbable. ¿Y por qué no pensar lo que ahora parece inverosímil, que en aquellos apartadísimos días, otros seres realizadores también del Espíritu, en otros mundos estuvieran en comunicación con los hombres y pudieran recoger, aprovechar, salvar lo mejor de la cultura humana? ¿Es esto fantástico, quimérico, extravagante? Llamadlo como gustéis, pero tampoco es improbable. Tendríamos entonces en el espacio universal el Espíritu, realizándose eternamente a través de formas transitorias y cada ser trantorio participando del sabor de lo eterno y de lo infinito, de lo divino en una palabra, al buscar su perfección".

("El Mercurio", Santiago de Chile, 20 de julio de 1952). 